\title{
A Study of Sleep disturbances in medically ill patients
}

\author{
Bindoo Jadhav ${ }^{1}$ \\ Hemangee S. Dhavale ${ }^{2}$ \\ Riddhish K. Maru ${ }^{3}$ \\ Priyanka Gupta ${ }^{4}$ \\ ${ }^{1}$ Professor, \\ ${ }^{2}$ Honorary Professor, \\ ${ }^{3}$ Consultant Psychiatrist, \\ ${ }^{4}$ Resident Doctor \\ Department of Psychiatry, K.J. Somaiya Medical College and Research Centre, Mumbai \\ E-mail - blmaru@gmail.com
}

\begin{abstract}
Sleep is one of the most significant human behaviors occupying roughly one third of human life. Prolonged sleep deprivation leads to severe physical and cognitive impairments \& finally death. Sleep disturbance may be a symptom of underlying medical illness or an adverse effect of therapy. This study was conducted to study prevalence and various types of sleep disturbances in patients with general medical illness and effect of duration of medical illness on sleep. All patients attending medical outpatient department of a general teaching hospital and patients willing to give informed consent were included in study. Patients with preexisting psychiatric illness or on psychiatric medication and those who were medically unstable/ critical were excluded. 150 consecutive patients attending medicine outpatient department in General Teaching Hospital were assessed. Semi-structured proforma specifically designed for the study was administered to patients to collect sociodemographic data and sleep related information. In our study, prevalence of sleep disturbances in patients with general medical illness was $74 \%$. In patients with general medical illnesses, type of sleep disturbances seen was Insomnia in $63.06 \%$, Restless leg syndrome in $22.52 \%$, Snoring in $21.62 \%$ and Narcolepsy in $18.01 \%$. $71.17 \%$ patients with acute medical illness and $28.82 \%$ patients with chronic medical illness were found to have sleep disturbances. Sleep disturbances in medically ill patients require careful evaluation for improving prognosis of underlying general medical illness.
\end{abstract}

Key words: sleep, sleep problems, medically ill, prevalence.

\section{INTRODUCTION}

Sleep disorders are among the most common clinical problems encountered in medicine and psychiatry. They may be primary or may result from a variety of psychiatric and medical conditions. Sleep disturbances occur in about $12 \%$ to $25 \%$ of the general population. In 1896, Acromegaly was the first endocrine disorder [1] recognized to be associated with heavy snoring and excessive daytime sleepiness. Sleep disturbance may be a symptom of underlying medical illness itself or may be an adverse effect of therapy. The prevalence of sleep disturbance tends to be higher in medically ill 
patients than in the general population. Poor sleep of patients with chronic illness may worsen the subjective symptoms of the disorder. If the quality of sleep is improved, subjective symptoms related to the disease may improve [2]. Sleep disorders such as poor sleep quality, insomnia, obstructive sleep apnea, snoring, restless legs syndrome and narcolepsy, are seen in medical disorders. Sleep disturbances are often cited by patients or primary caregivers as important sources of distress. Sleep disorders are acknowledged to be common but remain under-recognized and at times ignored by the medical community, often attributed to the failure to question patients about their sleep quality [3] and in part because of increasing time constraints and because of poor preparation to deal with sleep disorders [4-5]. Measuring sleep dysfunction is an area of active research, but few studies examined subjective ratings of sleep quality in medical patients so this study was conducted. The aims of the study was to assess the prevalence of sleep disturbances in patients with general medical illness, to study various types of sleep disturbances in such patients and to study the effect of duration of medical illness on sleep.

\section{METHODOLOGY}

- Site: Medicine out-patient department of general teaching hospital.

- Sample size: 150 patients.

- 150 consecutive patients attending medicine OPD and fulfilling inclusion criteria were included in study.

- Written informed consent was taken from the patients.

- Semi-structured proforma specifically designed for the study was administered to patients to collect socio-demographic data and sleep related information.

- Data thus collected was pooled and analyzed.

- Institutional ethics committee approval was taken.

\section{Inclusion Criteria -}

1. All patients attending medical OPD of a general teaching hospital.

2. Patient willing to give informed consent.

\section{Exclusion Criteria -}

1. Patients with pre-existing psychiatric illness or on psychiatric medication.

2. Patients who were medically unstable / critical.

\section{Statistical Analysis}

Descriptive statistics and percentage were used where appropriate.

\section{RESULTS}

In our study, out of total 150 patients assessed, 111 patients had sleep disturbances i.e. $74 \%$ patients had sleep disturbances. In the study sample, $51(45.9 \%)$ of the patients with sleep disturbances belonged to 20-40 years of age group. There was a female predominance with $56.75 \%$ of patients being females and $69(62.16 \%)$ patients were married. Almost half of the study population $(45.94 \%)$ had received primary education. 44 patients $(39.63 \%)$ were housewives \& 33 patients $(29.72 \%)$ were 
in service. In our study, about $2 / 3^{\text {rd }}$ i.e. $63.06 \%$ of patients having sleep disturbances had insomnia. Restless legs syndrome, a common neurologic sleep disorder, was found in $22.52 \%$ of the patients in our study which is higher than that found in normal population. Snoring was found in $21.62 \%$ i.e. 24 out of 111 patients. In our study, $18.01 \%$ subjects had narcolepsy which is much higher than that found in general population. $71.17 \%$ patients with acute medical illness and $28.82 \%$ patients with chronic medical illness were found to have sleep disturbances in our study.

Table - Sleep disturbances noted in the medical sample

\begin{tabular}{|cccc|}
\hline Illness & Number (\%) & Present in Males & $\begin{array}{c}\text { Present in } \\
\text { Females }\end{array}$ \\
\hline Insomnia & $70(63.06)$ & $29(26.13 \%)$ & $41(36.94 \%)$ \\
Restless leg & $25(22.52)$ & $8(7.2 \%)$ & $17(15.31 \%)$ \\
syndrome & & & \\
Snoring & $24(21.62)$ & $12(10.81 \%)$ & $12(10.81 \%)$ \\
Narcolepsy & $20(18.01)$ & $8(7.21 \%)$ & $12(10.81 \%)$ \\
\hline
\end{tabular}

\section{DISCUSSION}

The prevalence of sleep disturbances in our study is higher than that found in another study (50\%) [3] but lower than that found in some studies [6]. $(100 \%)$. A recent survey of outpatients attending hospital clinics showed the proportion of patients with sleep complaints ( $>70 \%$ ) was more than twice that among control subjects [7]. Women are at $41 \%$ greater risk for developing insomnia as compared with men and this risk increases with age [8]. In a study done by Meissner and others [3] insomnia was found in $47 \%$ of patients while other researchers have reported a prevalence of 59\% [9]. Numerous investigators have demonstrated increased prevalence of insomnia in subjects with somatic diseases [10-12]. Restless legs syndrome, a was found in $22.52 \%$ of the patients in our study which is higher than that found in normal population. A study done in the United States and Western Europe reported the prevalence of Restless legs syndrome as $5 \%$ to $10 \%$ of adults [13-18]. Meissner and others [3] in their study found the prevalence to be $25 \%$ which is similar to our study. Restless Legs Syndrome occurs more commonly in females [19]. Our study also shows that $15.31 \%$ of females as compared to $7.2 \%$ of males had Restless Legs Syndrome. In general population, Narcolepsy is rare with a prevalence of $0.04 \%$ [20-21]. The prevalence rate of narcolepsy in Southern (Hong Kong) Chinese was found to be $0.034 \%$ [22]. In our study, $18.01 \%$ subjects had narcolepsy which is much higher than that found in general population. Though in our study, sleep disturbances were found to be higher in patients with acute medical illness, other studies have reported the prevalence of sleep disturbances to be high in patients with chronic medical conditions [23-24]. In this study 150 consecutive medical patients were included hence there was no particularly clinical profile and they were just divided into acute and chronic illness groups. Some medical and psychiatric disorders share characteristics of narcolepsy, at times leading to diagnostic inaccuracy. Also, other sleep disorders are commonly comorbid. This may probably explain the higher prevalence of narcolepsy in our study [25]. 
This study highlights the significant prevalence of sleep disturbances in medically ill patients. These problems may be easily overlooked in medically ill patients. Sleep disturbances and their consequences are a matter of concern as they may be a risk factor for poor prognosis \& contribute to additional morbidity in these patients. Hence, assessment of sleep should be an essential component of the psychiatric evaluation in medically ill patients.

\section{REFERENCES}

1. Roxburgh R, Collis AJ. Notes on a case of Acromegaly. BMJ 1896;2:63-5.

2. Parish JM. Sleep-related problems in common medical conditions. Chest 2009;135:563-72.

3. Meissner HH, Riemer A, Santiago SM, Stein M, Goldman MD, Williams AJ. Failure of physician documentation of sleep complaints in hospitalized patients. West J Med 1998; 169(3):146-9.

4. Haponik E, Frye A, Richards B, Wymer A, Hinds A. Sleep history is neglected diagnostic information. J Gen Intern Med 1996;11:759-61.

5. Everitt D, Avorn J. Clinical decision-making in the evaluation and treatment of insomnia. Am J Med 1990;89:357-62.

6. Gislason T, Almqvist M. Somatic diseases and sleep complaints. Acta Med Scand.1987;221:475-81.

7. Kuppermann M, Lubeck D, Mazonson P. Sleep problems and their correlates in a working population. J Gen Intern Med 1995;10:25-32.

8. Klink M, Quan S, Kaltenborn W, Lebowitz M. Risk factors associated with complaints of insomnia in a general adult population. Arch Intern Med 1992;152:1634-7.

9. Cohen SD, Patel SS, Khetpal P, Peterson RA, Kimmel PA. Pain, Sleep disturbance, and Quality of Life in Patients with Chronic Kidney Disease. Clin J Amer Soc Nephrol 2007;2(5):919-25.

10. Mellinger G, Balter M, Uhlenhuth E. Insomnia and its treatment: prevalence and correlates. Arch Gen Psychiatry. 1985;42:225-32.

11. Ebrahami AA, Ghalebandi M, Salehi M, Alavi K. A comparative study of the components of sleep quality in medical outpatients. Int J Psychiatry Clin Pract 2009;13(3)184-7

12. Grond S, Zeck D, Diefenbach C, Bischof A. Prevalence and pattern of symptoms in patients with cancer pain: Prospective evaluation of 1635 cancer patients referred to a pain clinic. J Pain Symptom Manage 1994;9:37282.

13. Allen RP, Walters AS, Montplaisir J, Hening W, Myers A, Bell TJ, et al. Restless legs syndrome prevalence and impact: REST general population study. Arch Intern Med 2005; 165:1286-92.

14. Berger K, Luedemann J, Trenkwalder C, John U, Kessler C. Sex and the risk of restless legs syndrome in the general population. Arch Intern Med 2004;164:196-202.

15. Bjorvatn B, Leissner L, Ulfberg J, Gyring J, Karlsborg M, Regeur L, et al. Prevalence, severity and risk factors of restless legs syndrome in the general adult population in two Scandinavian countries. Sleep Med 2005;6:307-12.

16. Ulfberg J, Nystrom B, Carter N, Edling C. Restless legs syndrome among working-aged women. Eur Neurol. 2001;46:17-9.

17. Ohayon MM, Roth T. Prevalence of restless legs syndrome and periodic limb movement disorder in the general population. J Psychosom Res. 2002;53(1):547-54.

18. Phillips B, Young T, Finn L, Asher K, Hening WA, Purvis C. Epidemiology of restless legs symptoms in adults. Arch Intern Med 2000;160(14):2137-41.

19. Bentley AJ, Rosman K, Mitchell D. Gender differences in the presentation of subjects with restless legs syndrome. Sleep Med 2006;7(1):37-41.

20. Ohayon MM. Prevalence and comorbidity of sleep disorders in general population. Rev Prat. 2007;57(14):1521-8. 
21. Wing YK, Li RH, Lam CW, Ho CK, Fong SY, Leung T. The prevalence of narcolepsy among Chinese in Hong Kong. Ann Neurol. 2002;51:578-84.

22. Mucsi I, Miklos ZS. Sleep disorders and illness intrusiveness in patients on chronic Dialysis. Nephrol Dial Transplant 2004;19:1815-22.

23. Foley D, Ancoli-Israel S, Britz P, Walsh J. Sleep disturbances and chronic disease in older adults: results of the 2003 National Sleep Foundation Sleep in America Survey. J Psychosom Res 2004;56(5):497-502.

24. Smith MT, Haythornthwaite JA. How do sleep disturbance and chronic pain inter-relate? Insights from the longitudinal and cognitive-behavioral clinical trials literature. Sleep Med Rev 2004;8(2):119-32.

25. Peacock J, Ruth M. Narcolpesy : clinical features, cormorbidity and treatment. Indian J Med Res 2010;131:338-49.

Acknowledgements - Nil

Conflict of Interest - Nil

Funding - Nil. 